\title{
E-Government: Back-Office Systems Development - Critical Issues for the Greek Case
}

\author{
Stamatios A. Theocharis, George A. Tsihrintzis \\ Department of Informatics, University of Piraeus
}

\begin{abstract}
One of the major components of the electronic state is the e-administration, which must be supported by strong back office systems in order to increase efficiency and effectiveness of the administration. In this paper we examine the case of Greek Public Administration by researching the development of a back office system in terms of personalized service for government officials. We also present the basic desired characteristics of such a system which currently is under design.
\end{abstract}

\section{Introduction}

A lot of discussion has been made on egovernance and the need for changes in Public Administration in order to succeed in the transition to e-Government. The objective is to improve the quality and also expand the services provided to citizens and businesses, following the example of private sector companies. This issue is connected to the, so-called, Front Office of the Public Administration, that is, the person or representative of the public administration that any citizen deals with. Improving the Front Office is a point which governments consider as very important and emphasize its benefits to the everyday lives of citizens by applying e-government solutions. Thus, the focus now is on the citizen who deals with the administration and on how to serve him/her optimally. Special programs and individual assessments are underway to monitor the progress of the Front Office project. Moreover, e-Government encourages direct communication between citizens and policymakers enhancing democratic participation. Citizens enjoy the possibility, using innovative tools such as online forums, virtual discussion rooms, and electronic voting, of submitting questions directly to policy makers and expressing their views on the policies carried out by the public.

Considerable attention should also be paid to the other side of the issue of e-government that has to do with the support to the administration. Effort, therefore, has been made to improve the Back Office as well, i.e., the procedures and structures of institutions that support the delivery of public goods and affect the quality of the front office. The performance, efficiency and speed of the back-office will affect the overall image of public administration.

Importance similar to the one attributed to the image that citizens will form on e-Government should also be given to the appeal and to employees involved in the administration. If they have been offered modern, efficient and smart applications then maximum acceptance and support of the project will be achieved. Modern tools will enable faster and more effective solutions to everyday issues faced by the employee on the exercise of his duties. Particularly in the environment of economic crisis that plagued the previous year almost all the advanced states of Europe, the reduction of costs in the back office administration and faster service delivery is of great importance. The latter is directly related to the so-called paperless office. The transition from hard copy of documents produced to electronic documents and electronic procedures as well as electronic administrative transactions must be at the heart of policy. With such processes we can achieve the maximum degree of transparency and better control of the services involved.

This paper presents the main features and prerequisites that an integrated system must have in order to support an effective, efficient and modern back-office. More specifically, the paper is organized as follows: Section 2 reviews related previous work. Section 3 presents a brief reference to the current situation regarding the back-office systems in Greece, while Section 4 presents the main characteristics of the staff of the Greek government. In Section 5, we outline the main features that a system should have to support a paperless backoffice. Section 6 presents the prospects of such a system if it is supported by semantic web technologies. Section 7 presents the most critical issues for the back-office system development. Finally, Section 8 presents conclusions and points to future work on the subject of e-Government.

\section{Related work}

In a political, economic and social environment in which requirements for public administration are constantly increasing, the main goal for a system of servicing citizens and businesses is to provide integrated services and information that meets their objective standards of quality and efficiency.

The public needs to know in advance both the services and capabilities of the system provided and 
the standardization followed so as to promote a sense of confidence to the abilities of Public Administration and to the maintenance of proper procedures.

The system must fully meet the real needs of the public, for providing information and handling of administrative affairs in conjunction with the continuous review of procedures followed to ensure that the trade is more flexible and adaptable to continuously changing requirements. By the correct use of information communication technologies (ICT), transactions between the public and the public administration will be easier, faster and cheaper for both parties.

The improvement of the image of the State, the upgrading of relations between the state and social partners, and the transparency of operations, are directly related to the improvement of existing services, providing integrated electronic services to citizens and businesses and the transition to eGovernment. The provision of advanced electronic services, direct access to digitalized information are the key objectives of e-government whose main pillars are the electronic connection of public administration (e-administration) and interoperability between different information systems. To this end, the introduction of ICT in public administration is not the only prerequisite. Other prerequisites include the promotion of appropriate education, awareness and retraining of the employees, as necessary reforms to obtain a positive response from official executives and citizens.

In [1], the essential contributions of e-government are presented, including e-administration, while in [2] several aspects of developing an integrated Regional E-administration system are presented, by adding "pieces" successively developed under the frame of two PHARE Projects. In [3], the challenges and barriers of implementing e-government by the investigation on NEIS of Korea. In [4], issues are discussed that refer to the Manipulation and Transparency Control of an ICT-constituted eAdministrative Protocol via Digital Watermarking for LDC's. In [5], the authors contribute to the knowledge of the various issues raised by local eAdministration and propose an analytical framework for the evaluation of potential local online service offerings by the examination of how local public administration has been developed in France. In [6] a framework is proposed which is capable of personalizing both the access and the behavior of an e-office, based on ACE software. In [7], the authors deal with the typology of Citizenship management using ICTs, namely, e-administration, e-government, e-governance and "The Learning City". Finally, the authors in [8] present several aspects of building an integrated regional e-administration system. This system is a document-oriented data collecting network that ensures the link between the Timiş
County Council and the local administration and is based on Lotus technology.

\section{3. e-Administration - The current back- office in Greece}

In achieving e-government, special emphasis has been given so far in the implementation of infrastructure support as well as in software development in the front- office sector. Thus, as in all advanced countries, modern and powerful computers and peripherals have been installed and used throughout the Greek administration. Networks of public administration and broadband networks have been created and government websites and egovernmental portals have been developed in order to create the image of a modern and well-organized public administration focused on the user - citizen or business. Services have also been institutionalized which operate to the standards of one-stop-shop, but these are not authorized for the whole of government services. Of course, a lot of actions and steps still need to be taken for the provided services to reach their highest possible level of development.

All previous however, although initially accepted with great expectations for their subsequent evolution, have so far not had the desired results. From the point of view of the public, the new eservices, where implemented, have the greatest acceptance and penetration, while a large part needs further development or even revision. Noteworthy is the fact that people seem to trust the one-stop-shop services type to the provided online services until now. It seems that people prefer the personal touch and service from the employee rather than through an online self-service application. We can attribute it either to a lack of experience in the use of these services by the side of the public and the design of these services, which has the characteristics of personalization. The public seems to expect more, new and innovative online services, more intelligent and interactive applications, according to its own needs and skills as well as faster delivery of public goods.

On the side of the public sector (within the system of e-Government) expected cost savings and faster delivery of deliverables within the parties involved does not seem to currently be achieved. Direct consequences of this situation are recorded at prevailing view for the overall project to both employees and the public. One dimension of this problem is the need for structural changes in the state and its agencies and the need to develop innovative new applications in back-office.

Software applications developed are, in many cases, insufficient and deprecated to substantially assist the employee supporting the internal 
procedures. In particular, the existing systems are characterized by the following:

- Independent software applications do not support interoperability and standards that are developed on a case by case basis and occasionally overlap. We observe a phenomenon in various institutions: there are similar applications with similar functions that handle the same type of data but do not interact. As a result we do not really achieve the interconnection of all of public institutions. The consequences are higher government spending, waste of time when processing data which perhaps another public entity has already processed and incomplete or difficult control of the information whenever needed.

- Main emphasis is being given to the development of databases, which results into the same data being stored in many different computer systems. This fact in addition to the dimension of wasting storage space has also the perspective of potential errors and conflicts at the crosschecking of data due to double entries.

- Delay in application of universal electronic signatures. Although established through the adoption of relevant legislation, the validity of the electronic signature has not yet been possible to be used by nearly any of the public employees. This issue is crucial for the transition to another model of back-office function based on simpler processes and the reduction of printable documents resulting in lower costs, shorter processing times and higher transparency.

- Insufficient development of information systems to assist search of administrative information. The search of the necessary information when not covered by specialized depositories of certain organizations or when these are not recently updated is achieved through the common internet search engines without the possibility of specialized access.

- Procedures oriented to the, so-called, hard copy rather than electronic form on documents. This issue is linked to the existing institutional framework and the need to adopt new forms of administrative acts.

- Insufficient development of applications for recording and browsing processes and workflows. Given that such applications are specialized and non-commercial, their growth has come to a secondary role.

- As a consequence of the previous three issues, often searching for the necessary provisions, circulars or guidelines but also the data required for the processing of a case, requires sending documents between departments involved, resulting in wasting time and increasing spending.

The result of this situation is that employees in the back office of public administration, in many cases have to work just like they used to work several years ago, without being able to yield the expected. This problem is associated with the personalized provision of services that does not only concern the citizen or business, but also the employees of the government themselves, i.e., government-to-government (G2G) services.

\section{The current situation for the personnel of the Public Administration in Greece}

A major component of designing a software system is always the user. The interaction with the machine is crucial to its successful use, the employee's self-fulfillment and also as a means to achieve the targets set within the organization. By this term, the manufacturer of the system should create it, knowing in advance the actual needs and skills of the users. In this sense, the features of the human resources of public administration in Greece are very interesting.

According to available statistics for the entire workforce of the Public Administration [10], its main features are summarized as follows:

- Tendency of the percentage of University graduates to increase. As graduates of technical colleges and universities have become more familiar with the use of computers and new technologies in relation to older employees, applications installed or used may have greater acceptance than in earlier eras. This however has the dimension of stricter evaluation of existing applications from officials resulting in the obsolescence or even their complete withdrawal.

- Tendency of the staff to age. . This fact should be taken into account when designing new applications since older employees face particular problems with new applications

- Low percentage, though increasing, of women's participation in senior management positions(general directors and directors)

- Small proportion of disabled employees. The staff of this category usually has typically ancillary tasks such as in serving calls in call centers or clerical staff tasks. However, there are individuals with appropriate qualifications which could by using appropriate software to work in cutting edge sectors.

- Tendency of mass retirement of employees in conjunction with the severe restriction of new 
hires currently applied in the public sector. Coping with the economic crisis and the ever decreasing salaries, many employees prefer early retirement from the service. The phenomenon of mass retirement from the work in the public sector complicates the already difficult situation. This however is not without damage. These employees, having gained experience and knowledge retire and do not leave behind them this valuable heritage. This makes imperative issue the development of software that will help employees in acquisition and management of knowledge.

The personnel of the Public Administration, despite the efforts made in educational and training programs as well as in institutional measures, is still characterized by inherent, traditional dysfunctions such as the following [10]:

- The complexity of settings

- The uncertainty of settings and the contradictions between settings

- The fragmentation of production settings

- The existence of outdated settings which have not been adapted to modern technological data and new socio-economic requirements

- The absence of codification of existing settings

- Incomplete "official memory" of organizations

Some of the consequences of the above dysfunctions are:

- The burden to the government itself to carry out unnecessary paperwork

- The difficulty in searching for appropriate procedures for handling cases

- Delays and inefficiency in the delivery of public goods

- Difficulty in ensuring transparency in the acts of public administration and fighting corruption

- High cost of transacting with public services

- The disadvantage of citizens towards public services which trade with, especially those without a high skill, or knowledge on managing of their affairs, such as low educated people, immigrants, etc. and small businesses as well.

- The burden on the cost of living and quality of life of the citizens.

\section{Description of the Support System}

The current research examines the possibility of developing a single integrated system of support for the back-office of public administration within an organization's e-administration. The objectives of this system include:

Provision of the exact information and services needed by the employee depending on his/her position in the organization and especially on his/her particular skills. Obviously not all employees have the same needs and the same skills. However a common application for all would prevent disputes and conflicts When processing data and contribute to more cohesive function of the organization.

- Minimization of bureaucracy and production of hard documents. The new system should introduce innovations and support new processes to trigger the creation of new processes and ways of working in the public sector.

- Maximization of the organization's efficiency and effectiveness to achieve faster and more valid information search in accordance with the objective above.

- Providing tools for acquiring and managing knowledge. Public sector bodies have a huge amount of data and information while employees have transformed this wealth into knowledge. It is therefore necessary to develop specialized technologies to manage this knowledge

- Raising awareness of staff for effective system support. Employees who use a system are the ones who will note its defects and faults, or suggest improvements. They are also the ones to bring it out as a successful tool or reject it. There are cases where applications are constructed and manufactured according to the original requirements of employees but in practice have proven inadequate or inconvenient resulting in substantial removal.

- The interconnection and interaction with the systems of all public sector bodies under the current structure of the pyramid of Figure 1. According to this, there are two dimensions of interaction. One dimension concerns the hierarchical relationship between public bodies and the other, the direct relationship between public bodies with the public (citizens and businesses). In each dimension, back-office systems support interaction between bodies, and provide the requested data. These data are supplied to the intermediate handler who is the ultimate provider of services to the interested parties. 


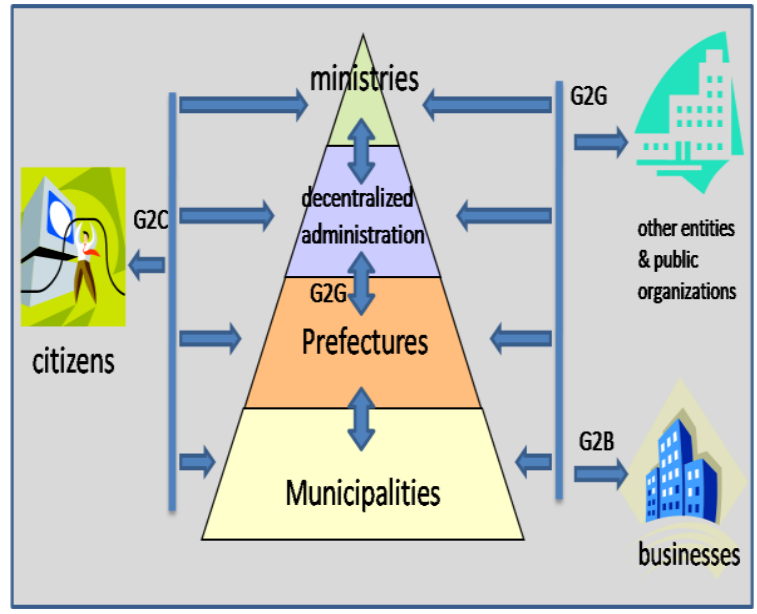

"Figure 1. The structure and interactions of the Greek public sector"

In order to determine the necessary structure of the system to support the operational function and the process of delivery of public services, system components have been classified according to the type of component implementation and the parties involved. These categories are:

- Users' access, meaning the user's point of contact with the system. This will be a channel of communication within the internal network of the organization (intranet) which will allow connection also to other users of the administration outside the institution may be in the form of an internal portal. This system will be personalized according to each employee so that every user can be recognized according to his/her personal and unique features, his/her position, his/her responsibilities in the institution, and his/her record of system use. In this way, any employee will transact with the system and have the most suitable choices and services. The same time the integration of employees into groups, based on specific user prototyping, which will handle specialized services will facilitate the processing of similar cases from employees working in different institutions.

- Interaction Services. This includes all the services offered to users in order to facilitate information. These are the most critical components of the system. The impact that they will have on employees will determine their success and further improvement of services of back-office. The main objective is personalized services and information based on innovative technologies such as the semantic web. These services cover all processes in the back-office: those hitherto made in the traditional way and are provided electronically.
These services will include depending on the position and duties:

- $\quad$ Specialized search engine featuring personalized information access. It is an extremely important function for saving time and increase efficiency and effectiveness

- Information on the processing stage and prediction for the final delivery of the service

- recommendations for any further actions needed

- Legalization of documents produced with the use of electronic signatures

- Check for legality of of incoming and outgoing documents. The control may relate to the confirmation of the issuer to the validity of data legalization of each document.

- Handling of electronically signed documents in subsequent levels of hierarchy until the final production of administrative acts.

- Automatic processing of documents and acts legalized

- Electronic procurement - Resource Management

- Personnel Management

- Support systems and interoperability. This means the systems that support these services and include:

- Software applications for managing information which has been developed based on open standards in order to support interoperability with relevant applications of other institutions

- Dynamic templates based on common standards for all public institutions

- A list with the works provided by the institution and workflow diagrams

- A list with the duties and responsibilities of the employees in order to ease the work distribution and to check the legality of administrative acts.

- Help desk with personalized access and semantic web features

- Hardware

- Communication and services interconnection tools. This means in addition to communication networks and applications the support of safe handling of information both within the organization and outwards. 


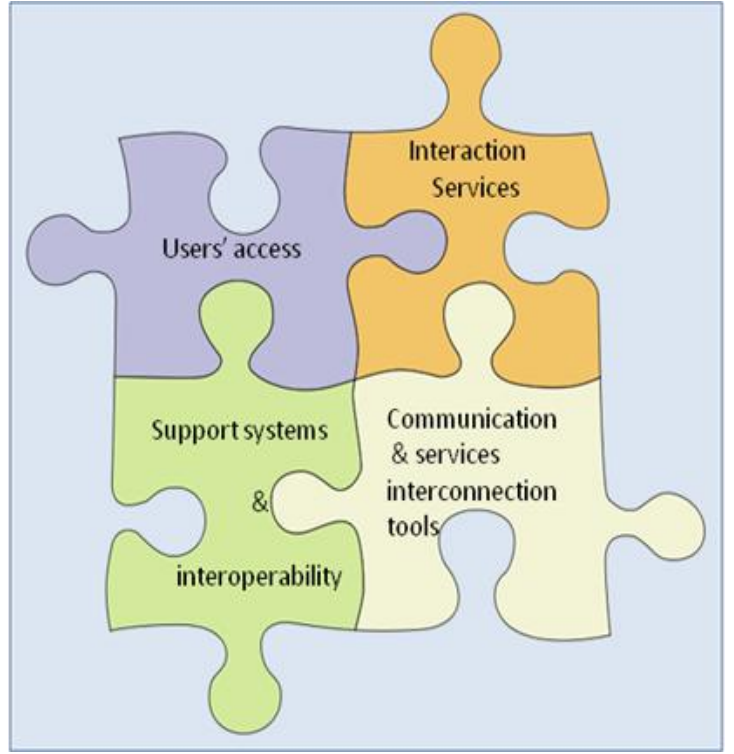

Figure 2: The parts of the back-office system

\section{Benefits of the System - Perspectives}

As already mentioned, an integrated public service system in e-governance, is mainly based on effective information systems. These systems on one hand support the internal informational public administration (back-office) and on the other hand are the interface between the Administration and the public. The key benefits of successful development include the following:

- Reduction of operating costs for the state

- Improvement of productivity and efficiency

- Maximization of the transparency of the procedures within the administration.

- Better service for the citizens who are the final recipients of services

- Support of decision-making

- Support of designation and realization of policies and programs

\section{Critical issues for the system development}

From another perspective, the issue of improving supporting structures is associated with redefining the responsibilities of ministries and public organizations since several shared services are frequently observed even within the same institution resulting in a more difficult transition to electronic delivery of these services. At the same time the huge amount of laws and circulars runs the risk of overlapping and conflicts between them. Part of the reforms for the restructuring of the management concerns designing automation processes and searching for innovative services by "building from scratch" the required procedures. In this case the design should be done in order to save time and money. This could be achieved through the adoption of new standards of organization of services, such as the so-called paperless office. The adoption of "green" models of organization and operation of public services that are focused on reducing operating costs such as costs for paper, printing costs and electricity might be an important step during the crisis. For this reason, it is necessary to study all the processes of an organization and decide which ones can be either combined or eliminated or automated or improved. Also the study on which of these can be converted into fully and exclusively electronic is particularly useful. All these can be achieved within the Business Process Reengineering (BPR) and the, so called, "administrative reform". It should however be taken into account that because of the existing institutional framework, changes and innovations in the public sector are promoted slowly or in any case slower than that in the private sector.

Moreover, one of the major factors for the further development of a new powerful back-office, is the preparation and training of human resources in the public sector. Our workforce is the one who will eventually recover or not the opportunities of technological solutions and decide whether to enter a new phase of work, attitude, perception and unmanning from the traditional way of working.

The questions asked by officials to address are:

- The adoption of customer-oriented concept whose ultimate purpose will be to satisfy the citizens within every act.

- The continuous and focused training in new technologies and the ability to interact with other departments and people.

- Increased participation in the targeting of the vector to become partakers of the new perceptions of work and contribution to society.

However, in this difficult path employees should receive the active support of the state and the superiors within the bosom of the organizations that will motivate them in the way of reorganizing the Public Sector. The service and the political leadership must act in this direction by applying specific policies such as:

- Focusing on how technology can influence and formulate strategies for the Public Sector

- Using technology for the development of innovation and not simply to automate processes

- Adopting the best practices from countries considered pioneers in e-Government 
- Improving the flow of financing to complete technological solutions

- Protecting the privacy and security

- Configuring communities within the workplace a commonly accepted technology development and the economy

- Using technology to create equal opportunities and

- Preparation for Digital Democracy.

Finally, an equally important success factor in developing an integrated back-office system is to secure funding. This is directly linked to the overall strategy of the government to finance policies to improve public administration. Nowadays, finding funds to support e governance is of fundamental importance for the future of the project. The main problems associated with this funding include the following:

-The difficulty of evaluating the benefits that can arise from investment, mainly economic-projects for the reorganization of the Public Administration,

- An inability to absorb EU funds concerning projects in Public Administration,

-Weakness of programming, forecasting and thus placing funds in the national budget of the country for the development of e-Government

- The economic crisis of the last three years.

\section{Conclusions and Future Work}

Under e-government, the public (individuals or businesses) are not involved in internal support processes of public administration, but only in the filling of the application form in the first place. The work required after the application becomes an issue of the public administration. The development of a strong back-office is an essential factor in achieving e-government. Important supportive factor is the simplification and automation of internal procedures followed in public administration as well as the effective assistance of human resources. The answer to the critical issues mentioned, is perhaps hiding in the administration itself. The utilization of public administration executives in the appropriate places, mobilization and sensitization of employees, the search and application of innovation and transformation of the structures of public administration according to new economic facts are the key concepts that should be used.

In this context future work includes the development of the systems mentioned above with an emphasis on supporting personalized access to information.

\section{References}

[1] HengWang, Jinchang Hou, "Main Contributions of EGovernance", International Conference on Computer Design And Applications, 2010

[2] Nicolae Robu, Vasile Stoicu-Tivadar, Ioan Silea, Lacramioara Stoicu-Tivadar, Dorin Berian, Adriana Albu, Gabriel Vlasiu, "Managing the Development of a Regional E-administration Network with Academic Expertise, IEEE, 2005

[3] Yong Soon KIM, Challenges and Barriers in Implementing E-government: Investigation on NEIS of Korea, ICAOT, 2006

[4] Syed Bahauddin Alam, A B M Rafi Sazzad, Md. Nazmus Sakib, Hussain Mohammed Dipu Kabir, Celia Shahnaz, Shaikh Anowarul Fattah, "Manipulation and Transparency Control of ICT constituted E-Administrative Protocol via Digital Watermarking for LDC's", IEEE, 2010

[5] Amel Attour-Oueslati, Denis Dufresne, and Christian Longhi, "The Development of the Local EAdministration: Empirical Evidences from the French Case", Springer-Verlag Berlin Heidelberg , 2007

[6] Jarogniew Rykowski, "Using Software agents to personalize access to e-offices", unpublished,

[7] Michael Willoughby, Hermenegildo Gil Go'mez, M. Angeles Fernandez Lozano, Making e-government attractive, Springer-Verlag, 2009

[8] S. A. Ahsan Rajon and Sk. Ali Zaman, "Implementation of E-Governance: Only Way to Build a Corruption-Free Bangladesh", Proceedings of 11th International Conference on Computer and Information Technology, 2008

[9] Hélène Michel, “ e-Administration, e-Government, eGovernance and the Learning City: A typology of Citizenship management using ICTs." The Electronic Journal of e-Government Volume 3 Issue 4, pp 213218, available online at www.ejeg.com

[10] Text from the "Operational Program : Administrative Refor 2007-2013”, Ministry of Interior, Greece, 2007.

[11] TREK Consulting A.E., study titled "the use of Information and Comunication Technologies in public sector", Observatory for the Information Society, 2007 